solution. Recognising that this opportunity might well not occur again they welcomed and endorsed the proposals, commending them to their constituents for detailed comment. In his addresses to the committees Mr Grabham, who paid tribute to the Minister for Health's initiative in setting up the group and to his colleagues on it, emphasised the importance of accepting the general thrust of the proposals: the details could be negotiated once the principles had been accepted. Moreover, the proposals would take 10 to 15 years to reach maturity, the aim was to balance the numbers of graduating doctors with career opportunities, and all parties in the discussions had made concessions_-a crucial one being to block the clinical assistant loophole by confining these posts to fewer than six sessions.

The two committees showed their political maturity in their willingness to endorse the proposals, their members acting in their true capacity as representatives and not delegates. Some members of the HJSC were worried about taking such a momentous decision without first referring back to their constituents, but a proposal to do this was overwhelmingly defeated. Clearly the great majority of members of the CCHMS and the HJSC felt that having debated manpower ad nauseam for 30 years or more they knew sufficient about the subject to come to a prompt and considered decision. On one important point, the BMA's opposition to a new subconsultant grade, Mr James Kyle, chairman of the representative body, reassured both meetings that in his view the new grade was not a subconsultant one in the sense that the representative body had debated it.

The government will have announced these proposals in parliament by the time this issue of the $B M \mathcal{F}$ is published, and the conference of royal colleges and the JCC will be discussing them shortly. If all parties can agree to proceed with discussions on this promising package of manpower proposals 1 January 1987, the planned time of introduction, may well go down as the day when the hospital doctors' tangled career structure at last began to form a coherent pattern. The initiative is both timely and welcome.

1 Parkhouse J. Manpower: compendium of deliberate mistakes. Br Med f 1986;292:1286-7.

\section{Managing Raynaud's phenomenon}

Although more than 100 years have passed since Maurice Raynaud first described his phenomenon its management strategies are still poorly defined. Recent editions of major textbooks are helpful only in dealing with more severe cases. ${ }^{1}$ Advances in our understanding of some of the pathophysiological processes in vascular disease, platelet behaviour, and blood rheology have created renewed interest in the disorder, however, and opened up possibilities of new approaches to treatment. Raynaud's phenomenon may be a symptom of a serious underlying disorder, such as systemic sclerosis or other connective tissue disorder, or-much more commonly -may present only as vasospasticity of the digits, sometimes also affecting the tip of the nose, tongue, or ears. This latter, primary form may be disabling but is rarely accompanied by complications such as tissue loss which are seen in the secondary form.
The management of primary Raynaud's phenomenon is firstly a task of educating patient and doctor about commonsense approaches to keeping warm. This may need to be backed up by treatment with relatively non-toxic drugs acting on the vascular system and possibly by attempts to improve the circulation with antiplatelet drugs or with drugs affecting red cell filterability.

Specific calcium channel antagonists-particularly nifedipine, verapamil, and diltiazem-have been reported to be effective in several studies. ${ }^{2-7}$ Some of these have included patients with both primary and secondary Raynaud's phenomenon; at Southampton we have studied mainly patients with primary Raynaud's phenomenon and confirmed the value of drugs of this class ( $D$ Waller and colleagues, unpublished data). Different calcium antagonists may act preferentially on different parts of the cardiovascular system, and this may need to be taken into account in choosing the drug, nor is there a uniform dosage regimen, but our experience suggests a range of 5-20 mg of nifedipine or 10-20 mg of its slow acting form. The side effects from this treatment are considerable-flushing, headaches, and ankle oedema - and may be enough to make it unacceptable.

Other vasodilator drugs, such as the nicotinic acid derivatives and oxpentifylline, are probably not as effective as the calcium antagonists.

Another group of drugs which may be useful are those which inhibit thromboxane synthetase or promote antiplatelet vasodilator effects, such as prostaglandin $E_{2}$ or its analogues. This line of treatment has been shown to be effective in patients with quite severe Raynaud's phenomenon, especially in cases where digits or even limbs appear to be at risk. ${ }^{8-10}$ Dazoxiben-a thromboxane synthetase inhibitor-has been reported to correct the increased concentrations of $\beta$ thromboglobulin reported in Raynaud's phenomenon; it does not affect the platelet factor 4 concentration, which tends to be normal anyhow. ${ }^{11}$ These results support the theory that platelet activation in vivo may be part of the mechanism causing the local effects in Raynaud's phenomenon. The problem with some of these drugs has been the need to give them by intra-arterial or intravenous infusion-as has also been the case with ketanserin, a 5-hydroxytryptamine receptor antagonist. ${ }^{12}$ Both ketanserin and dazoxiben, however, are becoming available in oral form. ${ }^{13}$

Other vasodilatory manoeuvres are being investigated, including the application of topical nitroglycerin ointment and transdermal prostaglandin analogues. ${ }^{14} 15$

Sympathectomy has been carried out for treatment of 을 Raynaud's phenomenon, but a questionnaire based study $N$ from the Dulwich Hospital reported in the Raynaud's Association Newsletter showed that the long term benefits were disappointing. ${ }^{16}$ Plasmapheresis has also been recorded as being of value, but it seems to have been superseded by more specific treatment. Biofeedback techniques have been reported to be useful. ${ }^{17}$ The criticisms of early trials of such techniques may well have been answered by more recent reports of sustained improvement on follow up. ${ }^{18}$

Probably many patients with primary Raynaud's phenomenon may benefit from slow calcium channel antagonists, but they may have to wait for new drugs - those currently available were designed mainly for other cardiovascular effects. Similarly newer developments in the category of thromboxane synthetase antagonists are also likely to become available as oral preparations. Patients with the more severe -usually secondary-forms of Raynaud's phenomenon may continue to require more aggressive treatment with \section{.}


intravascular infusions of prostaglandin $E_{2}$ analogues or combined vasodilator-antithromboxane treatment.

The Raynaud's Association Trust is a most helpful source of information for both patients and their doctors on topics ranging from electrically heated garments and hand warmers to digests of current research. Its publications are available from the secretary (A H Mawdsley, Raynaud's Association Trust, 40 Bladon Crescent, Alsagar, Cheshire ST2 2BG).

STUART ROATH

Senior Lecturer in Haematology,

University of Southampton,

Southampton General Hospital,

Southampton SO9 4XY

1 Gilliland BC, Mannik M. Progressive systemic sclerosis. In: Isselbacher KJ, ed. Harrison's principles of internal medicine. 9th ed. Tokyo: McGraw Hill, 1980:1900.

2 Smith CR, Rodeheffer RJ. Raynaud's phenomenon: pathophysiologic features and treatment with calcium-channel blockers. Am J Cardiol 1985; 55:154-7B.

Smith CR, Rodeheffer RJ. Treatment of Raynaud's phenomenon with calcium channel blockers. Am J Med 1985;78:39-42.

4 Kahan A, Amor B, Menkes CJ. A randomised double-blind trial of diltiazem in the treatment of Raynaud's phenomenon. Ann Rheum Dis 1985;44:30-3.

5 Kahan A, Weber S, Amor B, Saporta L, Hodora M, Degeorges M. Étude controllée de la nifédipine dans le traitement du phénomène de Raynaud. Rev Rhum Mal Osteoartic 982;49:337-43

6 Smith CD, McKendry RJR. Controlled trial of nifedipine-the treatment of Raynaud's phenomenon. Lancet 1982;ii: 1299-301.

Kinney EL, Nicholas GG, Gallo J, Pontoriero C, Zelis R. The treatment of severe Raynaud's phenomenon with verapamil. $\mathcal{F}$ Clin Pharmacol 1982;22:74-6.

8 Belch JF, Newman P, Drury JR, et al. Intermittent prostacyclin infusion in patients with Raynaud's disease. Lancet 1983;i:313-5.

9 Kyle V, Parr G, Salisbury R, Thomas PP, Hazleman B. Prostaglandin El vasospastic disease and thermography. Ann Rheum Dis 1985;44:73-8.

10 Sandhagen B, Wegener T, Haag A. Blood viscosity, finger systolic pressure and effect of Ddazoxiben treatment in primary vasospastic disease. Ups $\mathcal{F}$ Med Sci 1984;89:213-9.

11 Tindall H, Tooke JE, Menys VC, Martin MF, Davies JA. Effect of dazoxiben, a thromboxane synthetase inhibitor on skin-blood flow following cold challenge in patients with Raynaud's synthetase inhibitor on skin-blood flow followin
phenomenon. Eur F Clin Invest 1985;15:20-3.

12 Roald OK, Seem E. Treatment of Raynaud's phenomenon with ketanserin in patients with Roald OK, Seem E. Treatment of Raynaud's phenom
connective tissue disorders. Br Med f 1984;289:577-9.

13 Belch JJ, Madhok R, Shaw B, Leiberman P, Sturrock RD, Forbes CD. Double-blind trial of CL115,347, a transdermally absorbed prostaglandin E2 analogue, in treatment of Raynaud's phenomenon. Lancet 1985 ;i:1180-3.

14 Fischer M, Reinhold B, Falck H, Torok M, Alexander K. Topical nitroglycerin ointment in Raynaud's phenomenon. $Z$ Kardiol 1985; 74:298-302.

15 Dunger DB, Dillon MJ, Daman-Willems C, Cooke ED, Bowcock SA. Treatment of childhood Raynaud's disease by transdermal prostaglandin E2 analogue. Lancet 1985;ii:50.

16 Trafford J de. “The Raynaud's questionnaire." Raynaud's Association Newsletter 1985;14(Dec):2. 7 Yocum DE, Hodes R, Sundstrom WR, Cleeland CS. Use of biofeedback training in treatment of Raynaud's disease and phenomenon. I Rheumatol 1985;12:90-3.

18 Freedman RR, Ianni P, Wenig P. Behavioral treatment of Raynaud's disease: long-term followup. $\mathcal{F}$ Consult Clin Psychol 1985;53:136.

\section{Advances in the treatment of facial deformity}

The devastating combination of physical and psychological disability produced by facial deformity is unique. Attempts to correct both congenital and acquired malformations date from prechristian times, ${ }^{1}$ but they continue to tax the ingenuity of reconstructive surgeons. Recent advances in technique based on a better understanding of anatomy and physiology have made possible the treatment of some previously inoperable conditions and greatly improved the results in others.

The greatest innovator in this subject since Sir Harold Gillies is Paul Tessier. Stimulated by patients with grotesque deformities associated with severe Crouzon disease he developed radical operations now known as "craniofacial surgery." The two main underlying principles are, firstly, that large portions of the facial skeleton can be mobilised in the subperiosteal plane (that is, devascularised) and moved to a new position and survive; and, secondly, that even when there is gross abnormality of orbital relations (dystopia) the optic foramina are normally related. That means that the walls of the bony orbits may be cut and the eyes repositioned without destroying sight. The manoeuvre requires both intracranial and extracranial approaches and so a neurosurgeon must be brought in.

These techniques are most often used to treat deformities associated with premature fusion of cranial sutures (craniosynostoses). These may be isolated or part of a craniofacial dysostosis syndrome. The surgery is intended primarily to improve the appearance-but its impact is profound. Most patients are of normal intelligence, but because of the severity of their deformities have often been thought to be stupid-with intolerable effects on their daily life from childhood onwards.

Technical advances continue to be made. In particular, operations are being performed at a younger age, 6 months being the optimum for many patients. ${ }^{34}$ Apart from some practical surgical advantages this approach allows the rapidly expanding brain to be harnessed to mould repositioned bony structures and gives the child the psychological benefits of an improved appearance during his critical formative years. Furthermore, intracranial pressure is sometimes raised in these children without overt clinical signs. ${ }^{5}$ Without treatment the raised pressure may be associated with impaired intellectual development, but it is corrected in most cases by early surgery.

The development of a "team" approach implicit in such complex work has produced benefits for patients with many other types of deformity. The combination of plastic, neurological, oral, ear, nose, and throat, and ophthalmic surgeons backed by specialised anaesthetists, radiologists, orthodontists, psychologists, speech therapists, and nurses offers a great breadth of skills. Patients are usually seen jointly for a treatment plan to be established. The parents of a child with, for example, a cleft lip or Treacher Collins syndrome (mandibulofacial dysostosis, which may be extrem,ely deforming and associated with complex squints as well as problems of dental occlusion) will then know at an early stage when various surgical procedures are likely to be undertaken. Careful follow up and accurate record keeping are facilitated, eliminating unnecessary hospital visits but ensuring that opportunities for treatment are not missed. No aspect of treatment can be fully evaluated until growth is complete. The technological revolution in diagnostic radiology-from computed tomography to three dimensional imaging and nuclear magnetic resonance scanning-is providing increasingly accurate data on which to base surgery. ${ }^{6}$

One aspect of facial plastic surgery creating much interest is its place in children with Down's syndrome. Surgery can reduce the size of the tongue and lower lip, augment the chin and the profile of the nasal bridge, and correct the abnormally slanting eyelids and epicanthic folds. A report that such surgery improved the social acceptance and so the development and life opportunities for a girl with Down's syndrome ${ }^{7}$ has stimulated others to investigate its efficacy. ${ }^{8-10}$ The treatment remains controversial. Without doubt the facial stigmas of the syndrome may be modified, but claims that speech is improved have yet to be substantiated, and some critics argue that "normalisation" of the appearance may produce new problems. Behaviour patterns which are tolerated in a child recognised as having Down's syndrome may not be if he or she looks normal.

Facial deformity may also be due to trauma or a tumour and its surgical extirpation. Craniofacial techniques are often relevant in such cases. Progress in microsurgery has spawned a plethora of new options. Soft tissue, bone, and composite 